\title{
Ethanol Production from Schinus molle Essential Oil Extraction Residues
}

\author{
Jerry L. Solis ${ }^{1,2,3}$ (D) Robert Davila ${ }^{2}$. Camilo Sandoval ${ }^{2} \cdot$ Daniel Guzmán $^{2} \cdot$ Héctor Guzmán $^{2} \cdot$ Lucio Alejo $^{3}$. \\ Yohannes Kiros ${ }^{1}$
}

Received: 24 January 2019 / Accepted: 25 June 2019 / Published online: 28 June 2019

(c) The Author(s) 2019

\begin{abstract}
The present study determines the best conditions for the fermentation of Schinus molle drupes by the combination of different types of hydrolysis with the search for an adequate yeast strain. Schinus molle seed residues from an essential oil extraction plant (EOEP) have a high potential for ethanol production. Native yeast strains were isolated from the residues and were used to ferment the lignocellulosic residues, along with baker's yeast (Saccharomyces cerevisiae) at $30^{\circ} \mathrm{C}$ and $\mathrm{pH} 5.5$ for comparison. Morphological and biochemical characterizations were carried out on the isolated yeast strains. Thermogravimetric and high-performance liquid chromatography analyses were done on the S. molle seeds (fresh and residue) to determine the ethanol production potential. The followed methodology included increasing the sugar content by hydrolysis with chemical (sulphuric acid, acetic acid, and sodium hydroxide), physical (thermal, vacuum, and ultrasound), and enzymatic treatments (amyloglucosidase and $\alpha$-amylase). Once the optimum combination of yeast-hydrolysis was determined, a comparison of the greenhouse gas emissions between the original and proposed processes was done. The fermentation of the residues might replace methane from uncontrolled decomposition and reduce the solid residues in 50\%/day, hence the EOEP global warming potential is reduced by $47 \%$. The yearly income was estimated to increase by USD 2592.50 from $6302.6 \mathrm{~L}$ of ethanol produced from the residues.
\end{abstract}

\section{Graphic Abstract}

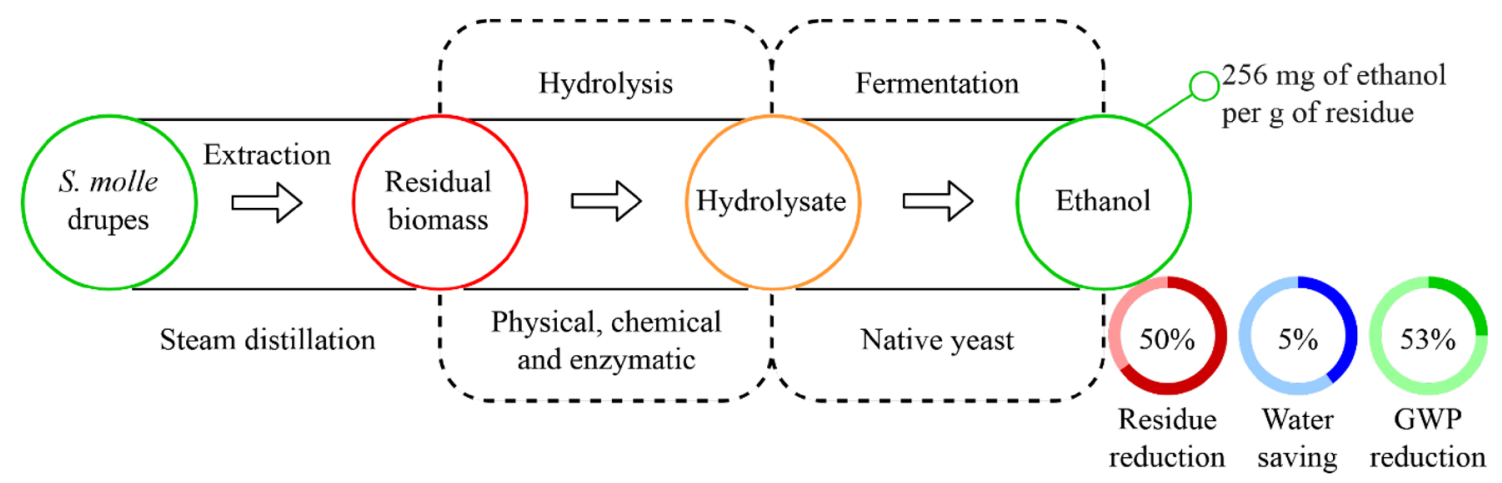

Keywords Schinus molle $\cdot$ Essential oil extraction $\cdot$ Ethanol $\cdot$ Native yeast $\cdot$ Waste treatment

\section{Statement of Novelty}

Jerry L. Solis

jlsv2@kth.se

Extended author information available on the last page of the article
Our research group identified the problem of accumulation of waste from the essential oil extraction units, since the essential oil yields are often low, the produced residue increases considerably. The current research proposes the 
decrease of the generated waste by producing ethanol. In order to achieve the ethanol production, several hydrolytic pre-treatments and fermentation conditions were used for a sector that is steadily growing for advancing second generation fuels. An approach in the treatment of lignocellulosic residues is proposed regarding the global warming potential, mass indicators, and additional means of income.

\section{Introduction}

Schinus molle is a tree belonging to the Schinus genus within the Anacardiaceae family, is prevalent in the semi-valley areas where the ground is moist but well drained [1], and the settled trees are drought resistant with soil tolerances as saline soils. The $S$. molle species are worldwide abundant as they are found as native species as well as anthropogenically inserted. The invasive species compendium from the Centre of Agriculture and Biosciences International (CABI) reports the growth of the plant in at least 40 countries, where the latitude and altitude vary from $25^{\circ} \mathrm{N}$ to $-35^{\circ} \mathrm{S}$ and 400 to $4200 \mathrm{~m}$, respectively [2]. The principal use of the plant is from the seeds, from which the essential oil is extracted. The dry mature drupes of the species are reported to have an average size of $6.35 \mathrm{~mm}$ [1] with an average fatty acid concentration of $5.35 \mathrm{wt} \%$ and essential oils concentration of $1.15 \mathrm{wt} \%$ [3]. A qualitative description of the drupes' sweetness by Goldstein and Coleman [4] was found but no further quantification of monosaccharides or polysaccharides has been found.

In Bolivia, the main uses of the plant are between ornamental and essential oil extraction. The essential oil extraction starts from the harvesting of the fruits, which are in racemes of drupes with sizes of $4.11 \pm 0.44 \mathrm{~mm}$ of diameter. Fruits are mechanically peeled and milled until approximately $99.4 \%$ are in a size particle of $\leq 850 \mu \mathrm{m}$. Once the particle size is fixed, the matter is placed in the distillation tank. Essential oils are extracted by steam distillation, where the essential oils are extracted from the freshly milled seeds. At the end of the process, the distillate is taken to a settler for phase separation while the residual biomass is discarded. In order to produce more than $100 \mathrm{~L}$ of essential oil per month, a plant would process $1430 \mathrm{~kg}$ of seed feedstock with $5.82 \%$ of essential oil content. After the extraction has concluded, the residual biomass is pumped out to the residue pool, while the essential oil is driven to a refining process. The residual biomass treatment consists in pumping the biomass sludge towards a landfill-like pool where it is left accumulating until it is retrieved by third parties for its use as land additive for various local crops.

The high residue output contrasts with the current need for more environment-friendly processes, calling to a proper management of residual biomass. The yearly production of essential oil at the scale of the processing plant described above derives in estimated $30,000 \mathrm{~kg}$ of $\mathrm{CO}_{2}$ produced from combustion and $1694 \mathrm{~kg}$ of greenhouse effect gasses (GHG) by the disposed residual biomass $(19,500 \mathrm{~kg}$ approx.). In addition to the high output of $\mathrm{CO}_{2}$ delivered to the atmosphere by the boiler, the production of methane gas add-up to the GHG that increase the negative effects caused by the process residues [5]. The actual management of these residues has a negative impact in the atmosphere, as well as on the land and water. Accounting the negative effects on the land, water, and surrounding vegetation are the biomass degradation leachates which cause eutrophication, e.g., increasing its biochemical oxygen demand (BOD) among other biochemical indicators [6]. On the evidence of the impacts of the produced residue, it is important to have an alternative to reduce the environmental impact. Hence, cleaner energy alternatives are being developed day by day and the available technology makes the lignocellulosic materials [7] to be suitable candidates for the production of second generation biofuels, e.g., ethanol from wood residues. The production of second generation ethanol has been studied from olive oil residues [8], spent coffee residues [9], rice straw [10], pineapple leaf and waste [11], wheat straw [12], sweet sorghum stalks [13], corn stover, lignocellulosic feedstocks [14], and even industrial orange residues [15].

The implementation of second generation biofuel processes within established processes is a proven strategy to increase the feedstock exploitation and decrease the residues [16]. The residues of the contemplated process constituted by the $S$. molle seeds, which at sight resemble a core heavily protected by a packed shell of hardwood [3]. Thus, the content of holocellulose would be higher than other second generation feedstock [17]. The microorganism activity found in the residue pool by the presence of bubbles and temperature higher than the ambient temperature proves that the nutrient levels are enough for the microorganism activity. The present study proposes the valorisation of the S. molle residues through a biotechnological mind-set, in addition to reduce the environmental impact of the essential oil extraction process (EOEP).

\section{Materials and Methods}

\section{Materials}

The Schinus molle mature drupes were collected from regional providers (farmers) in Cochabamba, Bolivia. The drupes were peeled and the resulting seeds were crushed in a plaque mill to have a particle size $<850 \mu \mathrm{m}$. The samples were stored at $4{ }^{\circ} \mathrm{C}$ in a sealed vessel and named "fresh sample" (FS) until further use. After the EOEP, the bagasse formed from the crushed seeds and water vapour 
was collected. The bagasse was then dried for $48 \mathrm{~h}$ at $60{ }^{\circ} \mathrm{C}$ in shallow trays avoiding any thermally activated reaction. After the bagasse was completely dried, it was ground to a size particle of $<500 \mu \mathrm{m}$. The biomass was stored in a sealed vessel and named "residue sample" (RS) until it was used in the experiment. The characterization of the biomass moisture, volatile matter, ash content, and fixed carbon was done via a Netzsch STA 449F3 thermogravimetric analyses (TGA) equipment.

The reagents used for the chemical hydrolysis were concentrated sulphuric acid (95-98\% reagent grade, SigmaAldrich), sodium hydroxide ( $\geq 97.0 \%$ ACS reagent, SigmaAldrich), hydrochloric acid (35-37\% AR, Sigma-Aldrich), $\alpha$-amylase from $A$. oryzae (>800 FAU/g, Fungamyl), amyloglucosidase from A. niger (>260 U/mL, Sigma-Aldrich), and deionized water (DIW). The neutralization of the solutions was done with $1 \mathrm{M}$ solutions of $\mathrm{HCl}$ and $\mathrm{NaOH}$. The evaluation of each hydrolysate monosaccharide content was performed with a Merck-Hitachi LaChrom HPLC system coupled with a D-7200 auto sampler. The column installed is Aminex HPX-87C $300 \times 7.8 \mathrm{~mm}$, with degassed DIW as the mobile phase. The injection method was in loop mode with a volume of $20 \mu \mathrm{L}$, at a constant temperature of $80^{\circ} \mathrm{C}$. The volumetric flow was constant at $0.6 \mathrm{~mL} / \mathrm{min}$. The detector used in the system was an IR $16 \times$ detector. The calibration curves were done with cellobiose, glucose, xylose, galactose, arabinose, and mannose. After the hydrolysis, each sample was centrifuged at 10,000 rpm for $10 \mathrm{~min}$ and the supernatant was filtered through $0.45 \mu \mathrm{m}$ PTFE syringe filters. The next step was to dilute the samples in a 1:10 volumetric ratio with DIW to be placed in the HPLC auto sampler sample tray.

The fermentation process required $5 \mathrm{~g}$ suspended biomass in $35 \mathrm{~mL}$ of DIW with the addition of calcium hydroxide (>95\%, Sigma Aldrich) with the $\mathrm{pH}$ fixed at 5.5. The ethanol content after the fermentation was measured via GC analyses. The equipment used was an Agilent GC 6890 using HP-FFAP polyethylene glycol capillary column $(30 \mathrm{~m} \times 530 \mu \mathrm{m} \times$ I.D. $1 \mu \mathrm{m})$ at an oven temperature of $215^{\circ} \mathrm{C}$ with helium as the carrier phase at a volumetric flow of $7.2 \mathrm{~mL} / \mathrm{min}$ and a split ratio of 80:1. The equipment has a flame ionization detector (FID) working at $300{ }^{\circ} \mathrm{C}$. Calibration curve was determined with $0.1,1.0,2.0,3.0$, and $10.0 \mathrm{vol} \%$. The sample preparation for the GC analysis consisted in centrifugation of the samples to obtain only the supernatant, which was filtered through a $0.45 \mu \mathrm{m}$ PTFE syringe filter and placed in the analysis tray.

\section{Characterization of the S. molle Feedstock}

The FS and RS samples were analysed by thermogravimetric analysis based on modified standards for moisture, ash content (ASTM E1755-01), volatile matter (ASTM E872-82), and proximal fixed carbon determinations. The modification was performed in terms of the initial mass, which was reduced to fit the equipment capacity. The moisture content was determined placing a crucible with $30 \mathrm{mg}$ of the samples (FS and RS) and carrying out the temperature increase up to $105{ }^{\circ} \mathrm{C}$ for $24 \mathrm{~h}$. Once it was proven that the mass remained constant, the weight of the samples was recorded and used for the further calculations. Afterwards, the samples were taken to the TGA equipment to undergo through the ash determination program as described in Table 1 under synthetic air atmosphere $\left(\mathrm{N}_{2} / \mathrm{O}_{2}\right)$. The volatile matter procedure is also listed in the Table 1, except that the atmosphere was $\mathrm{N}_{2}$ only.

The fixed carbon was determined by Eq. 1, where $\mathrm{m}_{\mathrm{FC}}$ stands for fixed carbon mass percentage, $\mathrm{m}_{\mathrm{M}}$ stands for moisture, $\mathrm{m}_{\mathrm{VM}}$ stands for volatile matter, and $\mathrm{m}_{\mathrm{A}}$ stands for ash content.

$m_{F C}=100-\left(m_{M}+m_{V M}+m_{A}\right)$.

\section{Main Monosaccharides and Klason Lignin Determination}

The monosaccharide profile of the $S$. molle seeds was determined with the standard SCAN-CM 71:09. The standard focuses in the determination of the content of five monosaccharides including glucose, mannose, galactose, arabinose, and xylose. Additionally, the method is complemented by Klason lignin determination by a gravimetric method. The extractives were calculated by proximity from the difference between the total biomass and the determined monosaccharides, Klason lignin, and ashes.

\section{Hydrolysis of S. molle Biomass}

The chemical hydrolyses were done with sulphuric acid, acetic acid and sodium hydroxide separately against a blank with water only. Additionally, since the standard for sugar quantification uses a vacuum followed by thermal treatment such treatments were tested with the chemicals afore mentioned. The hydrolysis started with $200 \mathrm{mg}$ of RS sample

Table 1 TGA temperature program for $S$. molle biomass characterization

\begin{tabular}{llll}
\hline Step & Rate $\left({ }^{\circ} \mathrm{C} / \mathrm{min}\right)$ & Time $(\mathrm{min})$ & $\begin{array}{l}\text { Tem- } \\
\text { perature } \\
\left({ }^{\circ} \mathrm{C}\right)\end{array}$ \\
\hline 1 & 5 & - & 220 \\
2 & - & 30 & 220 \\
3 & 5 & - & 550 \\
4 & - & 120 & 550 \\
5 & 5 & - & 900 \\
6 & - & 7 & 900 \\
\hline
\end{tabular}


Table 2 Chemical hydrolysis experiments

\begin{tabular}{llll}
\hline Hydrolysis & Compound & Vacuum & Autoclave \\
\hline 1 & $\mathrm{H}_{2} \mathrm{O}$ & + & + \\
2 & $\mathrm{H}_{2} \mathrm{O}$ & + & - \\
3 & $\mathrm{H}_{2} \mathrm{O}$ & - & + \\
4 & $\mathrm{H}_{2} \mathrm{SO}_{4}$ & + & + \\
5 & $\mathrm{H}_{2} \mathrm{SO}_{4}$ & + & - \\
6 & $\mathrm{H}_{2} \mathrm{SO}_{4}$ & - & + \\
7 & $\mathrm{NaOH}_{2}$ & + & + \\
8 & $\mathrm{NaOH}_{9}$ & + & - \\
10 & $\mathrm{NaOH}$ & - & + \\
11 & $\mathrm{CH}_{3} \mathrm{COOH}$ & + & + \\
12 & $\mathrm{CH}_{3} \mathrm{COOH}$ & + & - \\
\hline
\end{tabular}

with the addition of $3 \mathrm{~mL}$ of the hydrolytic compound at a concentration of $12.1 \mathrm{M}$ following the treatments detailed in Table 2.

After the hydrolysis was carried out, the mixture was levelled up to $35 \mathrm{~mL}$ of DIW to a $\mathrm{pH}$ of 7 with $1 \mathrm{M}$ of $\mathrm{HCl}$ and $1 \mathrm{M}$ of $\mathrm{NaOH}$ and filtered through $0.45 \mu \mathrm{m}$ PTFE syringe filter to fix the solutions at the HPLC operating conditions. A diaphragm pump with 9.0 mbar of vacuum capacity was used for the vacuum treatments, while an autoclave that reach a temperature of $121{ }^{\circ} \mathrm{C}$ with a pressure of $1.2 \mathrm{bar}$ was used for the thermal treatments.

An additional set of experiments were performed using ultrasound as it was reported that the pressure differences and the production of free radicals enhance the hydrolysis of lignocellulosic biomass $[18,19]$. The ultrasound was applied using a Sonics VC505 equipment with a $11 \mathrm{~mm}$ probe with $20 \mathrm{kHz}$ at $40 \%$ of power in pulses of $1-2$, i.e. $1 \mathrm{~s}$ of ultrasound pulse every $2 \mathrm{~s}$ of pause. The samples were prepared the same way as before, $3 \mathrm{~mL}$ of the $12 \mathrm{M} \mathrm{H}_{2} \mathrm{SO}_{4}$ added to $200 \mathrm{mg}$ of RS with ultrasonic treatment for $1 \mathrm{~h}$ inside a water bath. The same experiments were repeated with 12.1 $\mathrm{M} \mathrm{NaOH}$ and $12 \mathrm{M} \mathrm{CH}_{3} \mathrm{COOH}$ and water only samples.

The hydrolysis experiments were completed adding hydrolytic enzymes, such as $\alpha$-amylase and amyloglucosidase. Since the commercially available enzymes have high activity and concentration, $5 \mathrm{~g}$ of biomass were treated with enzymes. The preparation consisted in suspending $5 \mathrm{~g}$ of the RS biomass in $35 \mathrm{~mL}$ of DIW, supplemented with $20 \mathrm{mg}$ of $\mathrm{Ca}(\mathrm{OH})_{2}$ to ensure the bimetallic presence for the enzyme activity. The optimal hydrolysis conditions of each enzyme were used in the treatment of the $S$. molle residual biomass (RS). The $\mathrm{pH}$ and temperature were adjusted accordingly to each enzyme optimum as listed in Table 3. The volume of used enzyme was calculated considering the enzymatic activity of each enzyme, $260 \mathrm{UI} / \mathrm{mL}$ and $800 \mathrm{FAU} / \mathrm{g}$ for amyloglucosidase and $\alpha$-amylase, respectively. Additionally,
Table 3 Enzymatic hydrolysis experiments

\begin{tabular}{lllc}
\hline Enzyme & $\begin{array}{l}\text { Temperature } \\
\left({ }^{\circ} \mathrm{C}\right)\end{array}$ & $\mathrm{pH}$ & Volume $(\mu \mathrm{L})$ \\
\hline Amyloglucosidase & 70 & 5.5 & 427 \\
Amyloglucosidase & 70 & 5.5 & 1700 \\
$\alpha$-Amylase & 55 & 4 & 10 \\
$\alpha$-Amylase & 55 & 4 & 40
\end{tabular}

a $4 \times$ enzyme excess was planned to assess the maximum hydrolysable matter in RS.

After the enzymatic hydrolysis ended, the enzymes were denaturalized by thermal treatment in a boiling water bath. The samples were fixed to a $\mathrm{pH}$ of 7 and filtered through a $0.45 \mu \mathrm{m}$ PTFE syringe filter for its analysis in the HPLC equipment.

\section{Saccharomyces cerevisiae and Native Yeast Strains}

The first strain was obtained from the local supplier as bakers' yeast Saccharomyces cerevisiae. The isolation procedure started by taking samples from the sludge at the end of the EOEP, specifically from the land-fill like disposal area, which expels a characteristic odour of biomass decomposition with the presence of bubbles on the surface. Such samples were added to a laboratory flask with YPD liquid culture media. The native yeast strains grew on YPD culture broth, i.e., yeast extract (1 wt \%), peptone (2 wt \%), and dextrose $(5 \mathrm{wt} \%)$ suspended in DIW. In a second round of isolation procedure, the YPD culture broth was supplemented with 5 vol\% of ethanol. Further maintenance of the strains was carried by the use of solid culture media in petri dishes with the YPD culture media supplemented with $2 \mathrm{wt} \%$ of agar. Once the strains were isolated the identification and characterization were done. The morphological characterization was performed, including Gram test and yeast strain colony characterization. On the other hand, the biochemical characterization was done via bioMérieux API 20E and Remel RapID yeast plus identification kits.

\section{Fermentation Base Conditions}

Yeast strains were grown in YPD liquid culture medium to determine their growth curve. The culture medium was adjusted to $\mathrm{pH} 5.5$ at $24{ }^{\circ} \mathrm{C}$ with $200 \mathrm{rpm}$ of agitation. The growth rates were determined by the optical density in aliquots of $1.5 \mathrm{~mL}$ that were taken from the 4 th hour continuously every $4 \mathrm{~h}$ until $24 \mathrm{~h}$ were completed. Afterwards, the yeast was inoculated to the fermentation of the $S$. molle residues. The starting fermentation conditions were established using commercial yeast and the isolated yeast as described in Table 4. A Biochrom LibraS22 UV-Vis spectrophotometer 
Table 4 Fermentation base conditions

\begin{tabular}{lll}
\hline Conditions & Unit & Value \\
\hline S. molle matter & $\mathrm{g}$ & 5 \\
Yeast & $\mathrm{mg} / \mathrm{g}$ molle & 0.35 \\
Distilled $\mathrm{H}_{2} \mathrm{O}$ & $\mathrm{mL}$ & 35 \\
$\mathrm{Ca}(\mathrm{OH})_{2}$ & $\mathrm{mg}$ & 20 \\
Time & $\mathrm{h}$ & 24 \\
Temperature & ${ }^{\circ} \mathrm{C}$ & 30 \\
\hline
\end{tabular}

was used to measure the optical density of the samples at $600 \mathrm{~nm}$ of wavelength. The fermentable matter (FS or RS), yeast content, distilled water, $\mathrm{Ca}(\mathrm{OH})_{2}$, and temperature were constant in this experiments.

As the enzymatic treatment requires the addition of calcium, $20 \mathrm{mg}$ of $\mathrm{Ca}(\mathrm{OH})_{2}$ was added to all the experiments in order to null its effect. The reactor temperature was kept as reported by Tehrani et al. [9]. The reaction time was the first variable to study, where the aliquots were taken at 6,12 , 18, 24 and 36 h. Due to the possible stringency within the $S$. molle seeds' components, the yeast amount reached $70 \mathrm{mg}$ of yeast per gram of biomass. Additionally, the prepared culture broth was not autoclaved to maintain environmental conditions, i.e., the process require less energy. The initial measurement of the fermentation was evaluated with HPLC, having a comprehensible monosaccharide initial profile for each experiment. The results of the fermentation, monosaccharide and ethanol content, were measured by GC-FID and HPLC, respectively.

\section{Fermentation of the Hydrolysates with Nutritional Additives}

The fermentations were carried out using the hydrolysate (highest monosaccharide concentration) with the different yeasts to determine the highest ethanol production and later fermentation processes with the produced hydrolysates were performed. The conditions that exhibited the best ethanol production were supplemented by the addition of nitrogen sources as peptone and yeast extract at concentrations of $1 \mathrm{wt} \%$ and $2 \mathrm{wt} \%$, respectively. The data gathered until this point will be used for the improvement of the environmental impact of the EOEP.
Impact on Resource Productivity and Material Reuse

A mass balance analysis was carried out to measure the improvement of the process environmental impact, and it can be measured by several indicators as found in the literature. They include the e-factor, process mass intensity (PMI), mass productivity (MP), and reaction mass efficiency (RME) [20-22]. The e-factor, as well as the PMI, MP, and RME are based on the mass ratios, which are known variables in this work [23]. Additionally, the balances used for the environmental impact are a step closer to a life cycle assessment (LCA) [24-26]. The analysis is delimited to an EOEP with a processing capacity of $100 \mathrm{~kg}$ of $S$. molle seeds and includes a mass balance, as well as the process gas emissions on the established essential oil extraction process. The mass balances including the greenhouse gases were calculated for a facile comparison between the established process and the process coupled with the ethanol production from the residue. Furthermore, the yearly income increase from the produced ethanol was calculated based on the international FOB prices described by the U.S. Grains Council [27].

\section{Results and Discussion}

\section{Analysis of the S. molle}

Fresh seeds (FS) and residue seeds (RS) properties such as mass moisture, volatile matter, and ash content in a dry basis via TGA analyses are in Table 5. The major differences between the $S$. molle seeds, fresh and used, lie in the percentage of fixed carbon. When comparing with wood chips, forest residue, and sweet sorghum [28], the majority of the biomass is volatile matter, whereas in the $S$. molle samples resulted $10 \%$ less volatile mater, specifically in the FS sample.

The difference might be originated from the fact that different parts of one plant have different major components directly related to its physiological functions. In this case, the drupes and seeds have other role in the plant development. The water content (moisture) was different between FS and RS samples, and it will affect the resulting profile increasing the dry base content of volatile matter in RS. The high percentage of volatile matter present in RS, suggests the possibility to find RS a good feedstock for gasification.
Table 5 Biomass thermogravimetric analyses in dry basis compared to Ref. [28]

\begin{tabular}{lrrlcrc}
\hline Property & FS & RS & Forest residue & Wood chips & Sweet sorghum & Wheat straw \\
\hline Moisture (\%) & 16.6 & 7.6 & 6.3 & 3.9 & 7.0 & 10.3 \\
Volatile matter in air (\%) & 61.9 & 74.0 & $74.1-79.3$ & 80.0 & 77.2 & 77.7 \\
Ash (\%) & 9.1 & 5.4 & $1.3-4.1$ & 0.6 & 4.7 & 4.7 \\
Fixed carbon (\%) & 29.6 & 20.6 & $19.4-21.9$ & 19.4 & 18.1 & 17.6 \\
\hline
\end{tabular}


However, a close similarity was found when the RS samples are compared to the other lignocellulosic biomass in terms of fixed carbon. RS fixed carbon content is comparable to that of olive kernel (17.2\%) [29]. The higher content of fixed carbon in the FS samples suggest that might have higher heating value for additional applications. The content of ashes is higher in the FS and RS samples, suggesting the presence of higher mineral content than that of the forest residues, wood chips, and sweet sorghum. The higher content of minerals can be advantageous for the fermentation, reducing supplements added into the fermentation broth. The content of monosaccharides and Klason lignin were determined to share the biomass percentages presented in Fig. 1.

The sugar content analyses revealed that the glucose content is $16 \%$ for both FS and RS samples. Where the major component is observed to be the extractives, which for this study were calculated by the difference between the total biomass and the determined monosaccharide, Klason lignin and ash content. As the fermentation potential of the residues will be based on the carbon and nitrogen sources availability, and it is important to clarify that the extractives include the soluble lignin, proteins, and other soluble components as a whole [30]. The glucose content shows that the ethanol production from $S$. molle biomass is feasible (16 wt\%). The theoretical ethanol production based on the glucose content only would reach $82 \mathrm{mg}$ of ethanol per gram of $S$. molle seeds. Additionally, if all the monosaccharides are considered suitable to produce ethanol, such production could reach a theoretical $122.7 \mathrm{mg}$ of ethanol per gram of $S$. molle seeds. On the other hand, the dissolved lignin within the extractives might hinder the ethanol production due to microorganism inhibition [31,32]. The lignin also hinders the enzymatic activity by its competitive inhibition role [33]. Therefore, the lignin derivatives - aliphatic carboxylic acids, furan aldehydes, and acetic acid, among others-effects might be reflected in a lower ethanol yield depending on the yeast and enzyme resistances. These compounds are present as by-products of the common pre-treatments (acid, enzymatic, and hydrothermal pre-treatments) [34]. In the extractives share of the $S$. molle biomass, terpenes are the majoritarian components of the extracted essential oils. The concentration of terpenes in the FS samples not only might hinder the fermentation due to their reported high concentration of $1.5 \mathrm{~g} / \mathrm{L}$ [35] but could also limit the growth of other microorganisms due to the anti-microbial properties of the terpenes [36]. Additionally, the terpenes are also byproducts of the fermentation and the yeast strains might be accustomed to their presence.

\section{Biomass Hydrolysis}

The chemical hydrolyses resulted in a detection of a maximum amount of $14.36 \mathrm{~g} / \mathrm{L}$ of monosaccharides where $92 \%$ is identified as glucose detected after the treatment with $3 \mathrm{~mL}$ of a solution of $12.1 \mathrm{M} \mathrm{H}_{2} \mathrm{SO}_{4}$. The set of results presented in Fig. 2 show also that the most monosaccharides are released using $\mathrm{H}_{2} \mathrm{SO}_{4}$ when compared to $\mathrm{NaOH}$ and $\mathrm{CH}_{3} \mathrm{COOH}$. Because of the absence of vacuum treatment in the $\mathrm{H}_{2} \mathrm{SO}_{4}$ hydrolysis had a higher glucose release, the use of a $12.1 \mathrm{M}$ solution of $\mathrm{H}_{2} \mathrm{SO}_{4}$ with no treatment at all was considered (absence of vacuum and thermal treatments). Such experiment led to a value of $9.76 \pm 0.41 \mathrm{~g} / \mathrm{L}$ of glucose showing that the thermal method by autoclave is still the leading treatment.

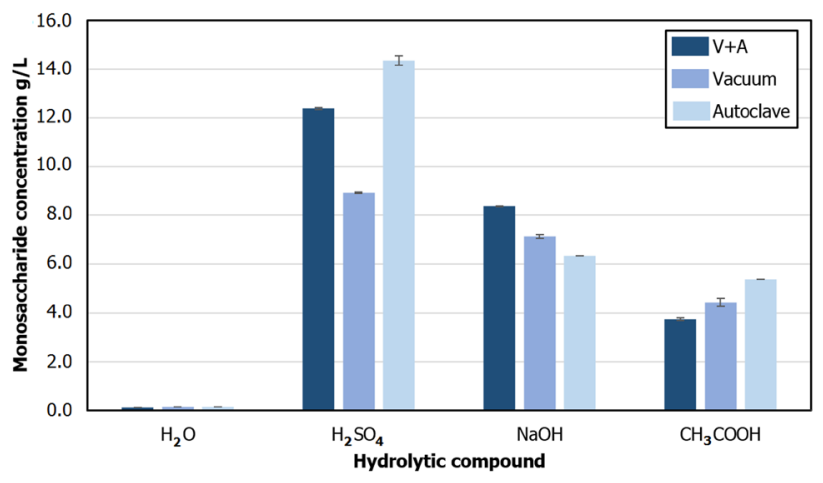

Fig. 2 Monosaccharide evaluation of RS hydrolyses (a)

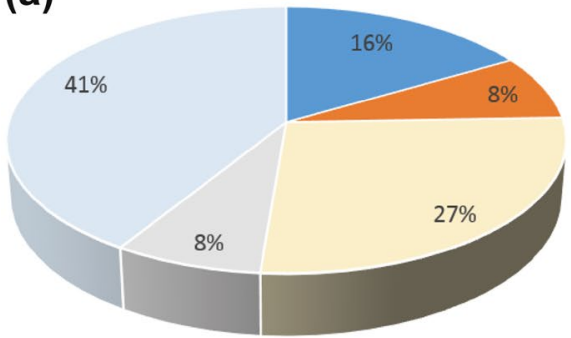

(b)

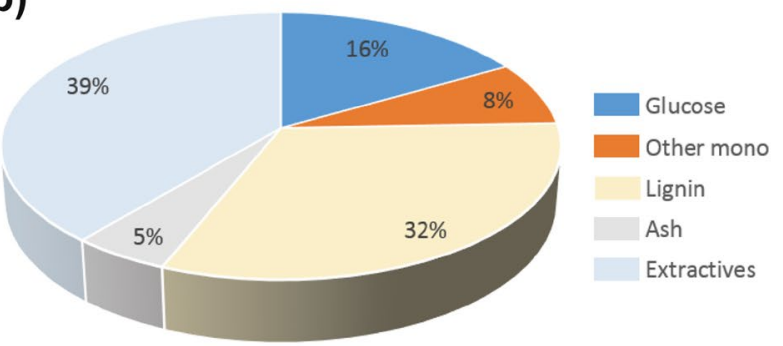

Fig. 1 Monosaccharide content analyses of the samples a FS and b RS 
The experiments with the ultrasonic treatment showed the results presented in Fig. 3. By the use of ultrasonic treatment, the maximum concentration of liberated monosaccharides reached $15.6 \pm 0.18 \mathrm{~g} / \mathrm{L}$. The $\mathrm{H}_{2} \mathrm{SO}_{4}$ hydrolytic effect was followed by the $\mathrm{NaOH}$ and $\mathrm{CH}_{3} \mathrm{COOH}$ in a decreasing trend. Another important observation is that the experiments with vacuum, steam explosion, and ultrasound showed the water-soluble monosaccharides is as low as $0.12 \mathrm{~g} / \mathrm{L}$.

The enzymatic hydrolyses released the monosaccharide concentrations showed in Fig. 4. In the enzymatic hydrolysis, it was determined that the amyloglucosidase has a higher activity, with the implication that the RS biomass has 1,4and 1,6- links in carbohydrates resulting in the release of $\alpha$-limit dextrin, maltotriose, maltose, and isomaltose. However, the resulting monosaccharide concentration from the $\alpha$-amylase is relatively lower, meaning that the surface of RS has a lower amount of amylose and amylopectin, i.e., lower 1,4- $\alpha$-glucosidic linkages to hydrolyse (maltose).

The carbohydrates present in the $S$. molle seeds are comprised by different kinds of polysaccharides plus a high amount of lignin, that might have a hindering effect on the enzymes' hydrolytic activity. The development stage where the seeds have more essential oil might also be determining for the carbohydrate composition [37], but to date no specific report on carbohydrates of $S$. molle seeds was found. Additionally, the blank had an apparent high concentration of monosaccharides due to the soluble matter under the $\mathrm{pH}$ and temperature conditions of the enzymatic treatments.

\section{Saccharomyces cerevisiae and Isolation of Native Yeast Strains}

The isolation procedure led to two yeast strains. One yeast strain grew on the YPD alone culture media, while the other yeast strain grew on the $5 \mathrm{wt} \%$ ethanol YPD and they were named Y1 and Y2, respectively. Both yeast strains resulted positive for Gram stain tests and the morphological characterization is listed in Table 6 .

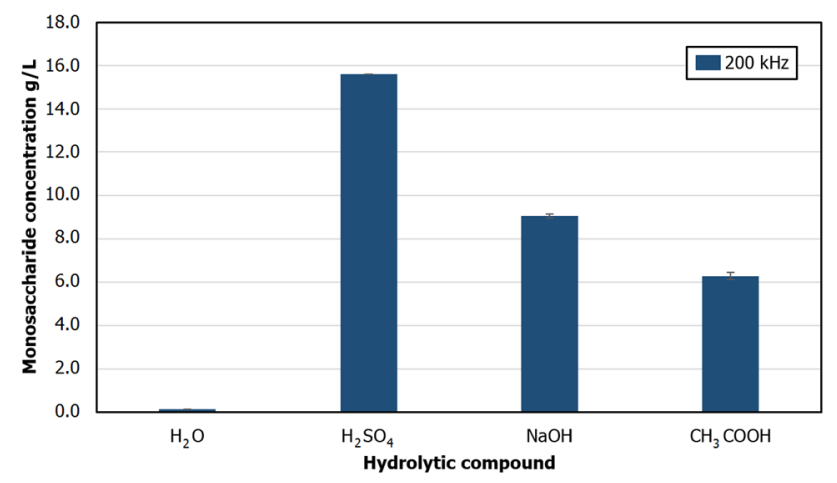

Fig. 3 Monosaccharide evaluation of RS ultrasonic aided hydrolyses

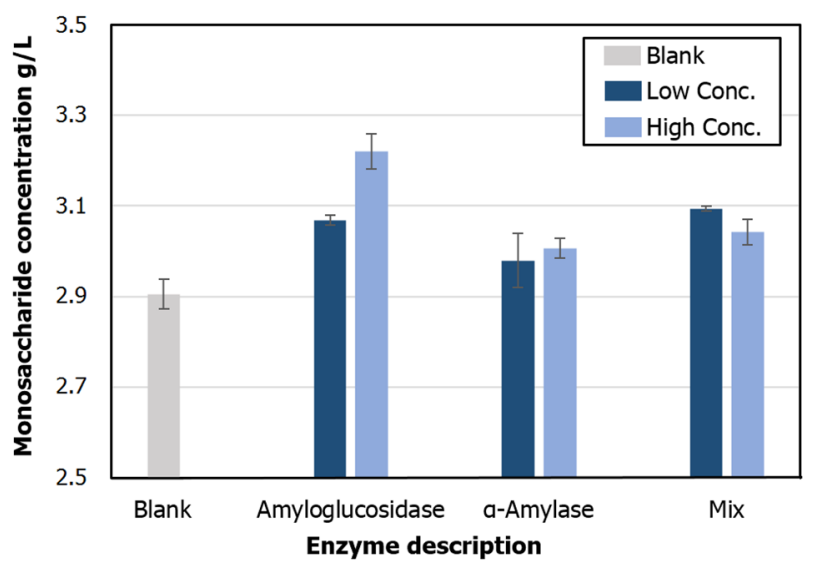

Fig. 4 Monosaccharide evaluation of RS enzymatic hydrolyses

Further characterization using the analytical profile index (API 20E) resulted in the characteristics described in Table 7. Among the results, the tests were positive for all the monosaccharides and polysaccharides included in the API 20E kit (glucose, sucrose, rhamnose, melibiose, and arabinose). The fermentation or oxidation were all positive as listed in the Table 7. The only enzyme production for detection of both yeast strains was for gelatinase. Enzyme tests for $\beta$-galactosidase, arginine dihydrolase, lysine decarboxylase, ornithine decarboxylase, and urease, resulted negative for both strains. The analysis of the RapID yeast plus kit indicated that the yeast strain $\mathrm{Y} 1$ has biochemical properties similar to Candida apicola with a $94 \%$ of positive hits in the test. The biochemical properties of $\mathrm{Y} 2$ had $83 \%$ of similarity to the species $S$. cerevisiae. However, the yeast identification has to be confirmed with further analysis, e.g., 18S rRNA and protein-coding gene analyses [38].

\section{Fermentation Evaluation}

On the contrary of the commercial bakers' yeast $S$. cerevisiae, which is readily usable, the isolated native yeast strains must be cultivated to be inoculated at their exponential growth for their optimal performance in the fermentation.

Table 6 Morphologic features of the isolated yeasts

\begin{tabular}{lll}
\hline Characteristic & Y1 & Y2 \\
\hline Gram test & + & + \\
Appearance & Circular & Circular \\
Margin & Smooth & Smooth \\
Elevation & Convex & Convex \\
Texture & Creamy & Creamy \\
Pigmentation & Seashell white & Seashell white \\
Optical property & Opaque & Opaque \\
\hline
\end{tabular}


Table 7 API 20E and RapID yeast plus characterization profiles

\begin{tabular}{llllll}
\hline \multirow{2}{*}{ Test } & \multicolumn{2}{l}{ API 20E } & & \multicolumn{2}{l}{ RapID } \\
\cline { 2 - 3 } \cline { 5 - 6 } & Y1 & Y2 & & Y1 & Y2 \\
\hline S-Galactosidase & + & + & & ND & ND \\
Gelatinase & + & + & & ND & ND \\
Glucose & + & + & + & + \\
Sucrose & + & + & + & + \\
Melibiose & + & + & & ND & ND \\
Arabinose & + & + & & ND & ND \\
Maltose & ND & ND & - & - \\
Trehalose & ND & ND & - & - \\
Rafinose & ND & ND & & + & + \\
Histidine $\beta$-naphthylamide & ND & ND & + & - \\
Leucyl-glycine $\beta$-naphthylamide & ND & ND & + & - \\
$\rho$-Nitrophenyl- $\alpha$, D-glucoside & ND & ND & - & + \\
$\rho$-Nitrophenyl- $\alpha, D-$ galactoside & ND & ND & - & + \\
\hline
\end{tabular}

$N D$ not determined

Accordingly, the growth curves in Fig. 5 indicate that the exponential growth for both yeast strains start at the 7 th hour until the 16th hour, and both reach quiescence state approximately at the 17 th hour. The established times for the aliquot extraction might have played a role in the determination of the growth curve for Y2. The growth curve for Y2 seems to be still increasing at the last point. However, due to the sampling times the maximum might have passed undetected between 16 and $20 \mathrm{~h}$. Further fermentation experiments were done inoculating the yeast at its exponential growth state, i.e., at the 10th hour.

The fermentations that were carried out with $S$. cerevisiae, $\mathrm{Y} 1$, and $\mathrm{Y} 2$ in their exponential growth state resulted in the ethanol production levels depicted in Fig. 6. The ethanol

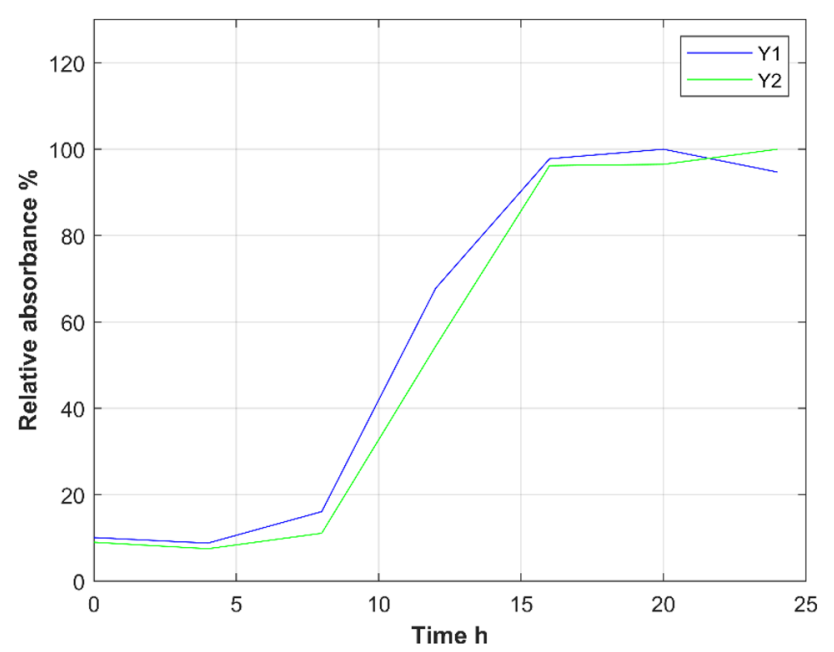

Fig. 5 Growth rate curves for the isolated yeast strains

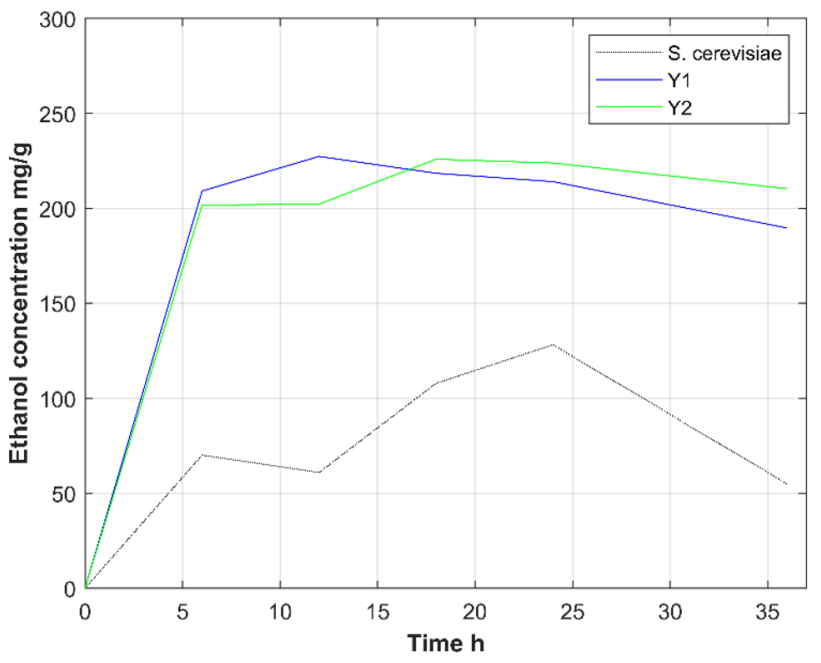

Fig. 6 Initial fermentation process

production is higher using both native yeast than using the $S$. cerevisiae. The ethanol production increased exponentially within the 6th hour, while the maximum was achieved at 12th and 16th hours, with Y1 and Y2, respectively. Additionally, the ethanol content is detected to reduce only $11 \%$ and $6 \%$ in the case of $\mathrm{Y} 1$ and $\mathrm{Y} 2$, while the decrease of ethanol content in the case of the $S$. cerevisiae fermentation process reaches a lowest of $57 \%$. Such decrease of the ethanol production is related to the acetic fermentation which is produced by the oxidation of ethanol called acetogenesis [39].

The data depicted in Fig. 6 shows that the ethanol content is stable from the 5 th hour until the 24th hour, and the $S$. cerevisiae has a continuous ethanol increase until that time, as a consequence the fermentation base conditions for FS and RS were kept for a $24 \mathrm{~h}$ fermentation time. The ethanol production of both biomass samples (FS and RS) resulted in the ethanol content values depicted in Fig. 7. The ethanol production for the fermentation evaluation shows that the yeast $S$. cerevisiae has the peak ethanol production within the fresh seeds samples (FS). The first possible explanation is that FS has a higher content of soluble sugar to be a facile carbon source available for the yeast biological processes, while the $S$. molle seeds residue has its soluble extractives stripped off by the EOEP. The second explanation is that the total content of the $S$. molle seeds might have controlled the growth of other bacteria keeping the fermentation by $S$. cerevisiae only. The difference on ethanol production by $S$. cerevisiae might also be used to estimate the carbon source availability, where a difference of $10 \mathrm{mg} / \mathrm{g}$ in ethanol production can be estimated to be caused by the reduction of $4 \mathrm{wt} \%$ of the fermentable carbon source. Such difference might be caused by the loss of soluble fermentable matter during the essential oil extraction. 


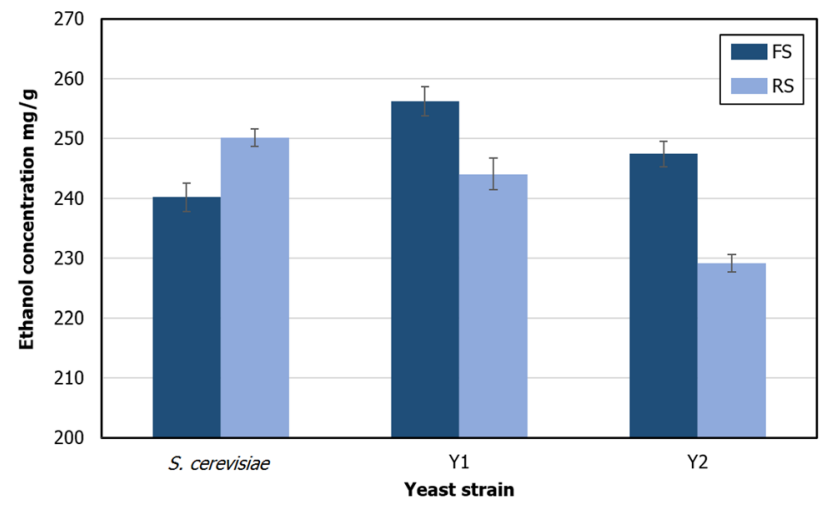

Fig. 7 Fermentation of FS and RS with the different yeast strains

The native yeasts $\mathrm{Y} 1$ and $\mathrm{Y} 2$ fermentations with the $S$. molle seeds residue (RS) had better results. Such difference might rely on the microorganisms adaptability to develop capacities that make them adapt to the surrounding environment $[40,41]$. Such mechanisms are even improved under long term nutrient stress [42], thus, improving the microorganism exploitation of the available nutrients. The ethanol production of the yeast $\mathrm{Y} 1$ is the highest of all with $256.3 \mathrm{mg} / \mathrm{g}$.

\section{Fermentation with the Hydrolysates}

Since the $\mathrm{H}_{2} \mathrm{SO}_{4}$ hydrolytic method resulted in highest monosaccharide release, as Fig. 8 indicates, the production of ethanol reached a maximum of $88.36 \mathrm{mg} / \mathrm{g}$ of $S$. molle residue (RS). However, by the use of a strong acid such as $\mathrm{H}_{2} \mathrm{SO}_{4}$ might lead to the production of high concentrations of $\mathrm{SO}_{4}^{-2}$ salts, that plus the by-products formed from lignin resulted in a yeast inhibition [43]. Furthermore, it is also important to highlight the increase of the ethanol production by the addition of yeast extract and peptone to the hydrolysate before the fermentation began. Such addition showed

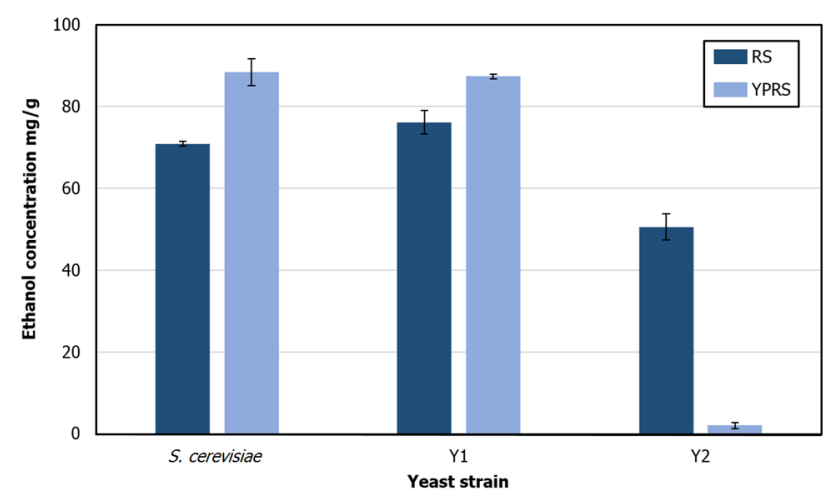

Fig. 8 Fermentations with the $\mathrm{H}_{2} \mathrm{SO}_{4}$ hydrolysate with different yeast strains that a lack of nitrogen-based nutrients might be hindering the ethanol production by the different yeast. The nitrogen sources, as well as carbon sources, play an important role in the longevity of the microorganisms affecting the overall production of ethanol [44].

The fermentation of the enzyme-driven hydrolysates was done afterwards with the results showed in Fig. 9. The combination of $\alpha$-amylase and amyloglucosidase (Mix) with the isolated yeast Y2 resulted in the superior ethanol production. The ethanol production of $S$. cerevisiae displayed that the enzymatic treatment with $\alpha$-amylase releases more fermentable matter (monosaccharides) than amyloglucosidase. Such result implies that the $S$. molle residual biomass (RS) might have more polymers composed by $1,4-$ and $1,6-\alpha$ linkages as in maltotriose, and amylopectin and dextran than higher oligosaccharides [45]. Additionally, the combination of enzymes resulted in a production of $102 \mathrm{mg} / \mathrm{g}$ with an amount of residual monosaccharides of $0.01 \mathrm{~g} / \mathrm{L}$. Likewise, the fermentation by the yeast $\mathrm{Y} 1$ showed that the combination of enzymes was advantageous for higher ethanol production, even if the obtained ethanol concentration was considerably lower $(88 \mathrm{mg} / \mathrm{g})$ than the fermentation with $S$. cerevisiae. The ethanol production with the yeast Y2 was higher than the previous production processes. The effect of $\alpha$-amylase increased the ethanol production to $88 \mathrm{mg} / \mathrm{g}$, while the effect of amyloglucosidase kept the same level of ethanol production as with the $S$. cerevisiae $(74 \mathrm{mg} / \mathrm{g}$ ), and the combination of both enzymes (Mix) showed an ethanol production of $111 \mathrm{mg} / \mathrm{g}$. The isolated yeast Y2 was identified to have a close similarity to $S$. cerevisiae, accordingly it is possible that both yeast strains have a less assimilation capabilities of some components released by the amyloglucosidase from the RS biomass. However, the combination of both enzymes led to the most advantageous monosaccharide content which in turn produced the highest concentration of ethanol as a result of a synergistic activity of the enzymes

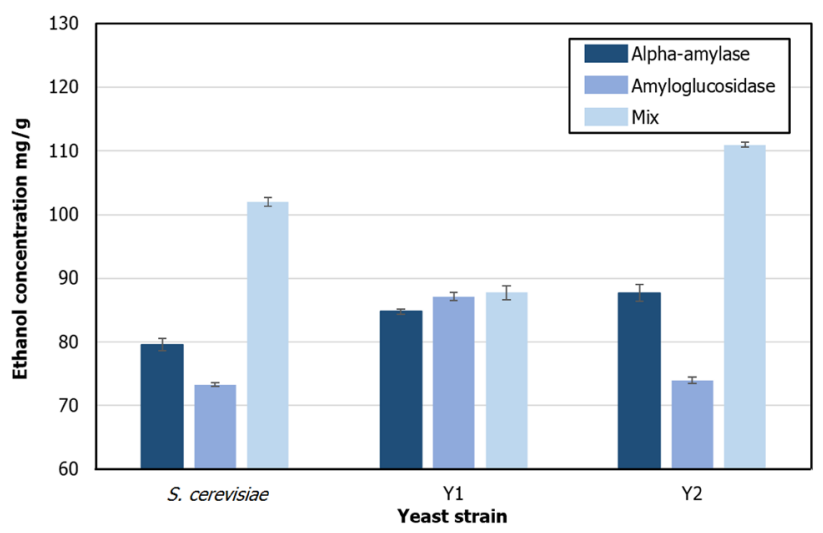

Fig. 9 Fermentations with the enzyme hydrolysates and different yeast strains 
[46]. The result might be explained by the selectiveness of the enzymes that combined release more fermentable matter from the residual biomass from $S$. molle (RS).

\section{Impact of the Fermentation in the Process}

Two mass balances were done to compare the impact between the present EOEP process and the proposed implementation. The first mass balance is depicted inside the blue-dashed box in Fig. 10, where the essential oil extraction process was evaluated as one operational unit. The assumptions include the consideration of optimal combustion of natural gas and air to $\mathrm{CO}_{2}$ and $\mathrm{H}_{2} \mathrm{O}$. The combustion feeds the boiler to produce steam, and only the material entering and leaving the process were considered for the purpose of this study. The peeling and milling operations normally consume electrical energy and were thus discarded for the calculations of the gas emissions. The $S$. molle residual bagasse was determined to be constituted by $18 \mathrm{wt} \%$ of $S$. molle seed residues (biomass) and $82 \mathrm{wt} \%$ of $\mathrm{H}_{2} \mathrm{O}$. An estimation of the greenhouse gases emitted from the uncontrolled decomposition of such mixture reached $6.49 \pm 1.21 \mathrm{~kg}$ of $\mathrm{CH}_{4}$ per dry $\mathrm{kg}$ of biomass per day [47]. The drupe peels and seed loss through the processes were estimated to reach $5.9 \mathrm{~kg} /$ day and were no further considered for any reusability. The water feed is considered as one input line of $700 \mathrm{~kg} / \mathrm{day}$. The outputs included water with the bagasse, as well as water from the combustion, water loss by the process inadequacies, and water separated from the essential oil.
The green-dotted box in Fig. 10 shows the system boundaries considered for the mass balance of the extraction process coupled with the fermentation of residual seeds process. The fermentation process was assumed to behave like a fed-batch process, where the yeast and bagasse are fed to the system as they come from the EOEP, and the ethanol is separated as it is produced. The importance of the improvement of the water recovery is evident, the fermentation process requires $618 \mathrm{~kg}$ of $\mathrm{H}_{2} \mathrm{O}$, which could be recovered water instead of adding potable water. The ethanol production was assumed to reach the best production conversion reached in this study (256 mg/g) and the biomass in the bagasse was also reduced reaching a $47 \mathrm{wt} \%$ of reduction. The $\mathrm{CO}_{2}$ production was also calculated based on the ethanol production, reaching $44.19 \mathrm{~kg} / \mathrm{day}$, which apparently is higher than the production of gases from the uncontrolled residue decomposition. However, the estimated GHG emitted from the uncontrolled decomposition (including $6.49 \mathrm{~kg}$ of $\mathrm{CH}_{4}$ per day) but the $\mathrm{CO}_{2}$ produced by fermentation has an infrared activity of 21 times lower than that of the $\mathrm{CH}_{4}$ on a 100-year time horizon [48]. According to the IPCC fifth assessment report (AR5), 2013 on the global warming potential (GWP), $\mathrm{CH}_{4}$ has a factor of 34 over a unit of $\mathrm{CO}_{2}$ for the 100-year time horizon [49]. As a result, the implementation of the residue fermentation could reduce $47 \%$ of GWP. The results on the comparison of the processes are listed in Table 8 by the indicators e-factor, process mass intensity (PMI), mass productivity (MP), and reaction mass efficiency (RME).

Even though the indicators listed in Table 8 are commonly used for synthesis and catalytic synthesis processes,

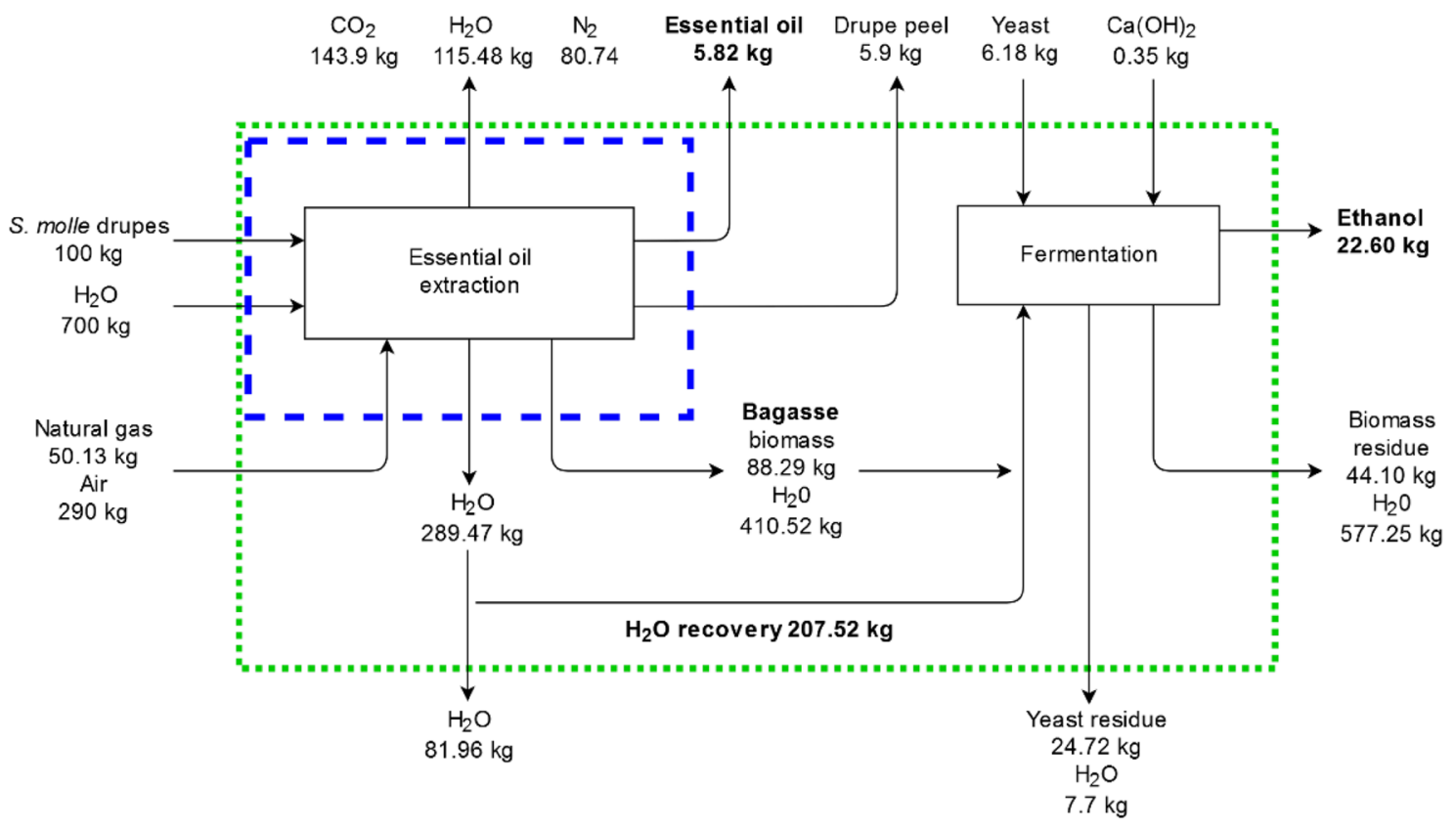

Fig. 10 Mass balances of the essential oil extraction and fermentation processes. (Color figure online) 
Table 8 Mass indicators for the comparison of the environmental impact improvement

\begin{tabular}{llll}
\hline Indicator & Definition & Extraction & $\begin{array}{l}\text { Extraction } \\
\text { and fermenta- } \\
\text { tion }\end{array}$ \\
\hline E-factor & $\frac{\text { Product } \mathrm{kg}}{\text { Total waste } \mathrm{kg}}$ & 9.54 \\
Process mass intensity (PMI) & $\frac{\text { Total mass used } \mathrm{kg}}{\text { Mass of total product } \mathrm{kg}}$ & 48.07 & 37.44 \\
Mass productivity (MP) & $\frac{1}{\text { PMI } \times 100}$ & 0.68 & 2.67 \\
Reaction mass efficiency (RME) & $\frac{\text { Mass of total product } \mathrm{kg}}{\text { Total mass used } \mathrm{kg}}$ & 0.007 & 0.027 \\
\hline
\end{tabular}

${ }^{a}$ Total waste does not include water such indicators show clearly the improvement of the EOEP by the coupling with a fermentation process. The e-factor decreases five times, while the PMI decreases approximately four times. On the other hand, the MP increases up to 2.67 and the RME considerably increases from 0.007 to 0.027 .

Based on the ethanol production established in the mass balance presented in Fig. 10, it might be possible to produce $22.6 \mathrm{~L}$ of ethanol per day. According to the U.S. Grains Council, 2019 the Houston "Free on board" (FOB) average price of ethanol from January-2018 to January-2019 ranged at US\$ 0.39 per litre, while the price in FOB Santos, and FOB Gulf were US\$ 0.476 , and US\$ 0.368 per litre, respectively [27]. Considering the differences that the ethanol price might have depending on the region, it was calculated that a yearly production of $6302.6 \mathrm{~L}$ of ethanol could lead to an income of US\$2592.50.

\section{Conclusions}

Schinus molle seed residues are suitable for a more sustainable essential oil extraction process and ethanol production. The biotechnological approach of isolating yeast from the residual disposal place reduces the local environmental consequences due to the insertion of foreign microorganisms into the local ecosystem. In this study the isolated native yeasts perform better than the commercial $S$. cerevisiae in different conditions. Whereas the isolated yeast $\mathrm{Y} 1 \mathrm{had}$ the best ethanol production in the bare RS fermentation and $\mathrm{H}_{2} \mathrm{SO}_{4}$ hydrolysate fermentations, the isolated yeast $\mathrm{Y} 2 \mathrm{had}$ a higher ethanol production in the enzymatic hydrolysate fermentation. The implementation of innovative technology approaches is advisable due to the increased potential of ethanol production, as determined by the effect of ultrasound in the hydrolysis treatments that showed comparable monosaccharide release to more energy intensive treatments such as vacuum and thermal treatments. The addition of the fermentation of $S$. molle seed residues might lead to an improvement of the impact of the extraction process. However, a study on the energy demand, the energy efficiency, and the energy demand of the proposed fermentation process could enlighten better the improvement. The potential of ethanol production from $S$. molle residues shows that the essential oil extraction process could be a more benign process as indicated by the adaptation of the quantitative metrics of e-factor, PMI, MP, and RME.

Acknowledgements This work was possible thanks to the financial support of the Swedish International Development Cooperation Agency (SIDA); KTH Royal Institute of Technology in Sweden; and UMSS Universidad Mayor de San Simon in Bolivia.

\section{Compliance with Ethical Standards}

Conflict of interest The authors declare that they have no competing interests.

Open Access This article is distributed under the terms of the Creative Commons Attribution 4.0 International License (http://creativeco mmons.org/licenses/by/4.0/), which permits unrestricted use, distribution, and reproduction in any medium, provided you give appropriate credit to the original author(s) and the source, provide a link to the Creative Commons license, and indicate if changes were made.

\section{References}

1. Garden, M.B.: Schinus terebinthifolius. Missouri Botanical Garden, St. Louis (2018)

2. CABI: Schinus molle, Invasive Species Compendium. CAB International, Wallingford (2018)

3. Pereira, M.P., Corrêa, F.F., Polo, M., de Castro, E.M., Cardoso, A.Á., Pereira, F.J.: Seed germination of Schinus molle L. (Anacardiaceae) as related to its anatomy and dormancy alleviation. Seed Sci. Res. 26, 351-361 (2016)

4. Goldstein, D., Coleman, R.: Schinus molle L. (Anacardiaceae) Chicha production in the Central Andes. Econ. Bot. 58, 523-529 (2004)

5. U.S. Environmental Protection Agency: O.o. Air and Radiation, Municipal Solid Waste Landfills Economic Impact Analysis for the Proposed New Subpart to the New Source Performance Standards, p. 62. U.S. Environmental Protection Agency, Research Triangle Park, Durham (2014)

6. Mwiganga, M., Kansiime, F.: The impact of Mpererwe landfill in Kampala-Uganda, on the surrounding environment. Phys. Chem. Earth 30, 744-750 (2005)

7. Ylitervo, P., Akinbomi, J., Taherzadeh, M.J.: Membrane bioreactors' potential for ethanol and biogas production: a review. Environ. Technol. 34, 1711-1723 (2013) 
8. Ballesteros, I., Oliva, J., Negro, M., Manzanares, P., Ballesteros, M.: Ethanol production from olive oil extraction residue pretreated with hot water. Appl. Biochem. Biotechnol. 98, 717-732 (2002)

9. Tehrani, N.F., Aznar, J.S., Kiros, Y.: Coffee extract residue for production of ethanol and activated carbons. J. Clean. Prod. 91, 64-70 (2015)

10. Soam, S., Kapoor, M., Kumar, R., Gupta, R.P., Puri, S.K., Ramakumar, S.S.V.: Life cycle assessment and life cycle costing of conventional and modified dilute acid pretreatment for fuel ethanol production from rice straw in India. J. Clean. Prod. 197, 732-741 (2018)

11. Seguí Gil, L., Fito Maupoey, P.: An integrated approach for pineapple waste valorisation. Bioethanol production and bromelain extraction from pineapple residues. J. Clean. Prod. 172, 1224 1231 (2018)

12. Zucaro, A., Forte, A., Fierro, A.: Life cycle assessment of wheat straw lignocellulosic bio-ethanol fuel in a local biorefinery prospective. J. Clean. Prod. 194, 138-149 (2018)

13. Ding, N., Yang, Y., Cai, H., Liu, J., Ren, L., Yang, J., Xie, G.H.: Life cycle assessment of fuel ethanol produced from soluble sugar in sweet sorghum stalks in North China. J. Clean. Prod. 161, 335344 (2017)

14. Bhutto, A.W., Harijan, K., Qureshi, K., Bazmi, A.A., Bahadori, A.: Perspectives for the production of ethanol from lignocellulosic feedstock: a case study. J. Clean. Prod. 95, 184-193 (2015)

15. Wilkins, M.R., Widmer, W.W., Grohmann, K.: Simultaneous saccharification and fermentation of citrus peel waste by Saccharomyces cerevisiae to produce ethanol. Process Biochem. $\mathbf{4 2}$, 1614-1619 (2007)

16. Gumisiriza, R., Hawumba, J.F., Okure, M., Hensel, O.: Biomass waste-to-energy valorisation technologies: a review case for banana processing in Uganda (report). Biotechnol. Biofuels 10, 11 (2017)

17. Anca-Couce, A., Obernberger, I.: Application of a detailed biomass pyrolysis kinetic scheme to hardwood and softwood torrefaction. Fuel 167, 158-167 (2016)

18. Bussemaker, M., Zhang, D.: Effect of ultrasound on lignocellulosic biomass as a pretreatment for biorefinery and biofuel applications. Ind. Eng. Chem. Res. 52, 3563-3580 (2013)

19. John, I., Pola, J., Appusamy, A.: Optimization of ultrasonic assisted saccharification of sweet lime peel for bioethanol production using Box-Behnken method. Waste Biomass Valorif. 10, 13 (2017)

20. Martinez-Guerra, E., Gude, V.G.: Assessment of sustainability indicators for biodiesel production. Appl. Sci. 7, 1-14 (2017)

21. Anastas, P.T., Zimmerman, J.B.: Innovations in green chemistry and green engineering selected entries from the encyclopedia of sustainability science and technology. Springer, New York (2013)

22. Sheldon, R.A.: Metrics of green chemistry and sustainability: past, present, and future. ACS Sustain. Chem. Eng. 6, 32-48 (2018)

23. Lipshutz, B.H., Isley, N.A., Fennewald, J.C., Slack, E.D.: On the way towards greener transition-metal-catalyzed processes as quantified by e-factors. Angew. Chem. Int. Ed. 52, 10952-10958 (2013)

24. Valdivia, S., Sonnemann, G., Canals, L.M.I.: LCA mainstreaming conditions in Latin America-based on learnings from 2005 to 2014. Int. J. Life Cycle Assess. 22, 485-491 (2017)

25. Davila, J.A., Rosenberg, M., Cardona, C.A.: Techno-economic and environmental assessment of p-cymene and pectin production from orange peel. Waste Biomass Valorif. 6, 253-261 (2015)

26. Moncada, J., Tamayo, J.A., Cardona, C.A.: Techno-economic and environmental assessment of essential oil extraction from Oregano (Origanum vulgare) and Rosemary (Rosmarinus officinalis) in Colombia. J. Clean. Prod. 112, 172-181 (2016)
27. U.S.G. Council: Ethanol Market and Pricing Data January 8, 2019, U.S. Grains Council, www.grains.org, pp. 1-11 (2019)

28. A. Moilanen: Thermogravimetric Characterisations of Biomass and Waste for Gasification Processes. Laboratory of Inorganic Chemistry, Åbo Akademi University, Otamedia Oy, Espoo, 103, +app.197 (2006)

29. Skoulou, V., Kantarelis, E., Arvelakis, S., Yang, W., Zabaniotou, A.: Effect of biomass leaching on $\mathrm{H}_{2}$ production, ash and tar behavior during high temperature steam gasification (HTSG) process. Int. J. Hydrogen Energy 34, 5666-5673 (2009)

30. Carvalho, D.M.D., Sevastyanova, O., Penna, L.S., Silva, B.P.D., Lindström, M.E., Colodette, J.L.: Assessment of chemical transformations in eucalyptus, sugarcane bagasse and straw during hydrothermal, dilute acid, and alkaline pretreatments. Ind. Crop. Prod. 73, 118-126 (2015)

31. Palmqvist, E., Hahn-Hägerdal, B., Galbe, M., Zacchi, G.: The effect of water-soluble inhibitors from steam-pretreated willow on enzymatic hydrolysis and ethanol fermentation. Enzyme Microb. Technol. 19, 470-476 (1996)

32. Wood, J., Orr, V., Luque, L., Nagendra, V., Berruti, F., Rehmann, L.: High-throughput screening of inhibitory compounds on growth and ethanol production of Saccharomyces cerevisiae. Bioenerg. Res. 8, 423-430 (2015)

33. Vermaas, J.V., Petridis, L., Qi, X., Schulz, R., Lindner, B., Smith, J.C.: Mechanism of lignin inhibition of enzymatic biomass deconstruction (report). Biotechnol. Biofuels 8, 217 (2015)

34. Jönsson, L.J., Martín, C.: Pretreatment of lignocellulose: formation of inhibitory by-products and strategies for minimizing their effects. Biores. Technol. 199, 103-112 (2016)

35. Dos Santos Cavalcanti, A., de Souza Alves, M., Da Silva, L.C.P., Dos Santos Patrocínio, D., Sanches, M.N., Chaves, D.S.D.A., de Souza, M.A.A.: Volatiles composition and extraction kinetics from Schinus terebinthifolius and Schinus molle leaves and fruit. Rev. Bras. Farmacogn. 25, 356-362 (2015)

36. Geyid, A., Abebe, D., Debella, A., Makonnen, Z., Aberra, F., Teka, F., Kebede, T., Urga, K., Yersaw, K., Biza, T., Mariam, B.H., Guta, M.: Screening of some medicinal plants of Ethiopia for their anti-microbial properties and chemical profiles. J. Ethnopharmacol. 97, 421-427 (2005)

37. Nkang, A.: Carbohydrate composition during seed development and germination in two sub-tropical rainforest tree species (Erythrina caffra and Guilfoylia monostylis). J. Plant Physiol. 159, 473-483 (2002)

38. Raja, H., Miller, A., Pearce, C.J., Oberlies, N.: fungal identification using molecular tools: a primer for the natural products research community. J. Nat. Prod. 80, 756-770 (2017)

39. Garrido-Vidal, D., Pizarro, C., Gonzalez-Saiz, J.M.: Study of process variables in industrial acetic fermentation by a continuous pilot fermentor and response surfaces. Biotechnol. Progr. 19, 1468-1479 (2003)

40. Brice, C., Cubillos, F.A., Dequin, S., Camarasa, C., Martinez, C.: Adaptability of the Saccharomyces cerevisiae yeasts to wine fermentation conditions relies on their strong ability to consume nitrogen (research article) (report). PLoS ONE 13, e0192383 (2018)

41. Jørgensen, H.: Effect of nutrients on fermentation of pretreated wheat straw at very high dry matter content by Saccharomyces cerevisiae. Enzyme Eng. Biotechnol. 153, 44-57 (2009)

42. Broach, J.R.: Nutritional control of growth and development in yeast. Genetics 192, 73 (2012)

43. McMillan, J.D.: Pretreatment of Lignocellulosic Biomass. Enzymatic Conversion of Biomass for Fuels Production, pp. 292-324. ACS publications, Washington, DC (1994)

44. Santos, J., Leitao-Correia, F., Sousa, M., Leao, C.: Nitrogen and carbon source balance determines longevity, independently of 
fermentative or respiratory metabolism in the yeast Saccharomyces cerevisiae. Oncotarget 7, 23033-23042 (2016)

45. Roberts, J.D.: Basic Principles of Organic Chemistry, 2nd edn. Calif, Menlo Park (1977)

46. Zhang, B., Dhital, S., Gidley, M.: Synergistic and antagonistic effects of $\alpha$-amylase and amyloglucosidase on starch digestion. Biomacromolecules 14, 1945 (2013)

47. Barlaz, M., Ham, R., Schaefer, D.: Mass-balance analysis of anaerobically decomposed refuse. J. Environ. Eng. 115, 1088$1102(1989)$

48. Barlaz, M.A.: Forest products decomposition in municipal solid waste landfills. Waste Manage. 26, 321-333 (2006)
49. Stocker, T.F., Qin, D., Plattner, G.-K., Tignor, M., Allen, S., Boschung, J., Nauels, A., Xia, Y., Bex, V., Midgley, P.: Climate Change 2013: The Physical Science Basis, Working Group I Contribution to the Fifth Assessment Report of the Intergovernemental Panel on Climate Change, vol. 1535. Intergovernmental Panel on Climate Change, Cambridge University Press, Cambridge and New York (2013)

Publisher's Note Springer Nature remains neutral with regard to jurisdictional claims in published maps and institutional affiliations.

\title{
Affiliations
}

\section{Jerry L. Solis ${ }^{1,2,3} \mathbb{1 0} \cdot$ Robert Davila $^{2} \cdot$ Camilo Sandoval $^{2} \cdot$ Daniel Guzmán $^{2} \cdot$ Héctor Guzmán $^{2} \cdot$ Lucio Alejo $^{3}$. Yohannes Kiros ${ }^{1}$}

\author{
Robert Davila \\ rObbertdavila@gmail.com \\ Camilo Sandoval \\ camilo.sandoval.po@gmail.com \\ Daniel Guzmán \\ ma.guzman@umss.edu.bo \\ Héctor Guzmán \\ he.guzman@umss.edu.bo \\ Lucio Alejo \\ lalejo@fcyt.umss.edu.bo
}

Yohannes Kiros

yohannes@kth.se

1 Department of Chemical Engineering and Technology, KTH Royal Institute of Technology, 10044 Stockholm, Sweden

2 Centro de Biotecnología, FCyT Universidad Mayor de San Simón, Cochabamba, Bolivia

3 Centro de Tecnología Agroindustrial, FCyT, UMSS

Universidad Mayor de San Simón, Cochabamba, Bolivia 